\title{
The life of Roger Williams
}

\author{
Author: Michael Glynn ${ }^{A}$
}

\section{In this brief obituary, we celebrate the life and achievements of Professor Roger Williams, who set up the UK's first liver transplant programme and championed excellence in hepatology for six decades.}

KEYWORDS: Roger Williams, obituary, hepatology, transplant, liver

DOI: $10.7861 /$ clinmed.obit.20.5

The death of Professor Roger Williams on 26 July 2020 marks the end of an era in which specialities were created by individuals whose names were instantly recognisable (in 2020 we also lost Bill Frankland who 'invented' the speciality of allergy). Having worked under Sheila Sherlock at the Royal Free from 1959, Roger joined Kings College Hospital in 1966, and always said that having Shelia as a 'rival' spurred him on to greater achievements. Within two years, on 25 September 1968, in collaboration with Prof Sir Roy Calne in Cambridge, the first UK/European liver transplant was undertaken. The first 10 years of this transplant programme were marked out by a cycle of poor results because transplant recipients had to be very ill to be considered. Nowadays, an oversight committee might well halt a clinical research programme that was making such little headway. The pursuit of better results, and the current routine nature of transplantation, is a testament to the drive and stamina of those pioneers.

Roger was born in 1931 and attended St Mary's College, Southampton. Having been in hospital with diptheria, he determined to study medicine and entered the London Hospital Medical College in 1949, one year after the founding of the NHS. He formally retired in 1996, but then set up the Foundation for Liver Research at UCH, which eventually moved back to Kings in 2016, as the Institute for Liver Studies. He married twice, and had a total of eight children, seven of whom survive him and one of whom is a physician. He managed to find time for outside pursuits including opera, farming and tennis, and it was while playing tennis that he had a fatal heart attack.

Author: ${ }^{A}$ consultant gastroenterologist and hepatologist, Barts Health NHS Trust; national clinical director GI and liver diseases for NHS England, 2013-6
His research and academic interests were so diverse that virtually every field of hepatology benefited from his vision and drive for excellence. He could easily have been a constructive reviewer of all the articles in the CME section of this issue of Clinical Medicine. He authored more than 2,500 papers, and achieved fellowship of many Colleges (FRCP, FRCS, FRCPE, FRACP, FMedSci, FACP [Hon]). Almost every liver centre in the UK, and many across the world, are now enriched by staff who were trained by Roger, trainees who will say that they put up with his many idiosyncrasies while hugely valuing his teaching, training, and subsequent support as they branched out. When they became his peers, they were no longer in awe of him, but valued his central coordinating role and vision, as well his boundless energy and longevity. A 2008 article in this journal gives his own perspective on the dramatic changes he had seen in his lifetime. ${ }^{1}$

He remained an active and passionate advocate for improving the care of patients with liver disease literally to the end of his life. One regret was that although he had close involvement with 'Conservative Health', he was unable to persuade the current Government in England to pursue a Minimum Unit Pricing policy for alcohol. Amazingly, in 2014, aged 83, he helped set up the Lancet Commission on Liver Disease and guided it through six annual reports, which have been extremely influential in increasing the profile of and funding for the care of UK liver disease patients.

\section{Reference}

1. Williams R. Hepatology: a personal story. Clin Med 2008;8:25-31.

Address for correspondence: Dr Michael Glynn, Royal London Hospital, Whitechapel Road, Whitechapel, London E1 1FR, UK. Email: consultant@glynngastro.net 